\title{
Análise petrofísica dos reservatórios carbonáticos microbiais da Formação Barra Velha, Pré-sal da Bacia de Santos, Brasil
}

\author{
Luciana Castro Brelaz ${ }^{1 *}$, Mariléa Gomes dos Santos Ribeiro², Iraima Silva Mendes
}

${ }^{1}$ Universidade do Estado do Rio de Janeiro (UERJ), ${ }^{2}$ Universidade Federal do Pará (UFPA)

Copyright 2019, SBGf - Sociedade Brasileira de Geofísica

This paper was prepared for presentation during the $16^{\text {th }}$ International Congress of the Brazilian Geophysical Society held in Rio de Janeiro, Brazil, 19-22 August 2019.

Contents of this paper were reviewed by the Technical Committee of the $16^{\text {th }}$ International Congress of the Brazilian Geophysical Society and do not necessarily represent any position of the SBGf, its officers or members. Electronic reproduction or storage of any part of this paper for commercial purposes without the written consent storage of any part of this paper for commercial
of the Brazilian Geophysical Society is prohibited.

\section{Abstract}

This paper presents the petrophysical evaluation of one exploratory well of the Lula Field corresponding to the sag phase of the Santos Basin based on the well log interpretation that includes basic well logs (gama, caliper, neutron, density, resistivity, and sonic curves) and special logs (nuclear resonance magnetic). The reservoir rocks comprise stromatolites, spherulites and their intermediate facies with a clay-rich micritic matrix, interlayered to mudstones (and/or microbial laminites). These rocks exhibit calcitic composition with clay content less than $6 \%$. The average porosity is $6 \%$ to $7 \%$ reaching up to $23 \%$. The deep resistivity is greater than 100 ohm.m with an expressive invasion profile and annulus effect. Water saturation is less than $45 \%$ and the irreducible water saturation is less than $1 \%$. Due to lower water saturations the estimated permeability is high, with average values higher than $3 \mathrm{mD}$ reaching up 1,7 darcys in vugular and fractured layers. The pore geometry is characterized by macropores, where micropores make up less than $1 \%$ of the porous space. Silicification is a factor that negatively affects the reservoir reducing porosity; on the other hand, there is no direct relationship between dolomitization and porosity increase. Recrystallized and dolomitized limestones (with significant percentages of dolomite), shows a reduction of permo-porous conditions due to the increase of micro and mesoporosity.

\section{Introdução}

A descoberta do Pré-sal foi um marco para a indústria do petróleo no Brasil. Em pouco mais de 10 anos de exploração, a produção nos campos do Pré-sal já supera a marca de 1,8 milhões de barris de óleo equivalente por dia (Mboe/dia) e corresponde atualmente a 54,9\% da produção nacional de petróleo (ANP, 2019). Os microbialitos do Pré-sal são heterogêneos, estratificados, altamente permeáveis, possuem qualidade de reservatório variável e colunas de óleo superiores a 200 m (BOYD et al., 2015). Nos últimos anos, pesquisadores tem buscado compreender como os constituintes primários do arcabouço e a diagênese impactaram no sistema poroso dos carbonatos do Pré-sal da Bacia de Campos, fornecendo informações petrofísicas relacionadas a porosidade e permeabilidade destes reservatórios (HERLINGER et al., 2016; HERLINGER; ZAMBONATO; DE ROS, 2017; LIMA; DE ROS, 2019; (MACHADO et al, 2012). Para a Bacia de Santos raros trabalhos fazem alusão às condições permo-porosas destes reservatórios, acrescentando poucas informações acerca da quantificação das propriedades petrofísicas e a sua correlação com as facies sedimentares (BOYD et al., 2015). Este trabalho apresenta a avaliação petrofísica dos reservatórios carbonáticos microbiais da Formação Barra Velha com base em dados de perfis geofísicos pertencentes ao poço exploratório descobridor das gigantes acumulações do Pré-sal: o poço pioneiro 1-RJS628 (1-BRSA-369A-RJS), localizado no Campo de Tupi (atualmente Campo de Lula), situado na Bacia de Santos. O Campo de Lula é o maior campo produtor de petróleo e gás na atualidade e a Bacia de Santos a maior produtora de petróleo e gás dentre as bacias sedimentares brasileiras (ANP, 2019).

O poço 1-RJS-628 está situado em regiões de águas ultraprofundas a $2134 \mathrm{~m}$ de profundidade, distante cerca de $250 \mathrm{Km}$ ao Sul da cidade do Rio de Janeiro. Este poço teve por finalidade "testar a trapa estrutural ao nível dos carbonatos e arenitos da Formação Barra Velha (andares Alagoas, Jiquiá e Buracica) e embasamento fraturado, com alvo nos carbonatos do andar Alagoas ( 5050 m) e Jiquiá $(5150 \mathrm{~m})$ (Relatório Final de Poço Exploratório RFP-EX). Para este poço não houve corte de testemunho; as descrições litológicas estão baseadas em amostras laterais e de calha. O fluido de perfuração utilizado foi base óleo (Oil Based-Mud - OBM) para enfrentar as dificuldades operacionais e geológicas da perfuração da coluna de sal com 1916 m de espessura que estão sobrepostos a estes carbonatos.

A sucessão litoestratigráfica atravessada pelo poço 1RJS-628 do topo para a base tem início nos folhelhos da Formação Marambaia (em 2154 m) e base nos basaltos da Formação Camboriú $(5957 \mathrm{~m})$. Os carbonatos microbiais da Formação Barra Velha estão em contato concordante no topo com os evaporitos da Formação Ariri $(4950 \mathrm{~m})$ e discordante na base com as coquinas da Formação Itapema (5270,5 m) (Figura 1). A partir da integração das informações litológicas e da interpretação das curvas de poço foi possível determinar neste trabalho os parâmetros petrofísicos de porosidade, saturação, permeabilidade e geometria dos poros dos reservatórios carbonáticos microbiais depositados na fase Sag da Bacia de Santos. 


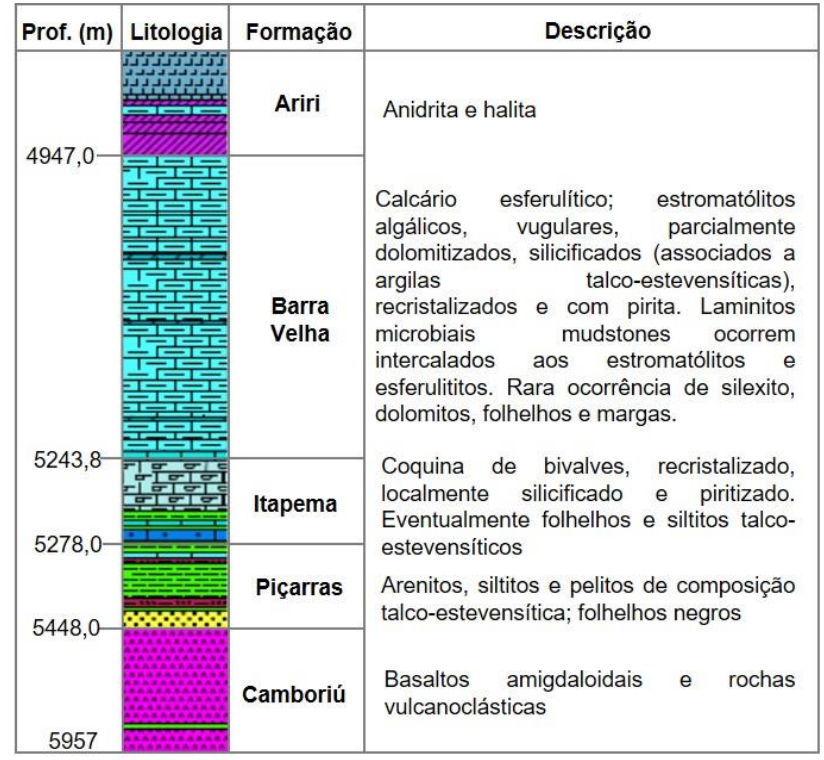

Figura 1 - Perfil litoestratigráfico esquemático do poço 1 RJS-628. Adaptado de MOREIRA et al. (2007).

\section{Métodos}

O poço 1-RJS-628 foi selecionado por conter uma espessa sequência de carbonatos da Formação Barra Velha, além de dispor de um pacote de dados completo para a avaliação petrofísica. Os dados de poço foram cedidos pela Agência Nacional do Petróleo (ANP) e incluem perfil composto, relatório final de poço exploratório (RFP-EX), descrições de amostras laterais e de calha, dados de perfuração e perfis de poço em formato las. As curvas de poço analisadas foram: raios gama (GR), cáliper (CAL), sônico (Dt), densidade (RHOB), neutrônico (NPHI), resistividade profunda (AT), sônico e ressonância magnética nuclear (RMN). Os perfis de poço foram processados no software TechLog ${ }^{\circledR}$ v.2015, disponível no Laboratório de Interpretação Sismoestratigráfica da Universidade do Estado do Rio de Janeiro (UERJ) por meio do convênio firmado entre UERJ, Equinor e ANP. As curvas básicas foram utilizadas para quantificação da argilosidade (a partir dos valores máximos e mínimos da curva de raios gama), porosidade e densidade da matriz (nêutron-densidade), saturações de água (método de ARCHIE, 1952 com uso dos parâmetros padrão $a=1 ; m, n=2)$ e permeabilidade absoluta (equação de COATES et al., 1991). A partir dos perfis de RMN foi possível obter informações acerca da porosidade, permeabilidade e parâmetros geométricos dos poros utilizando como base a classificação do tamanho de poros proposto por RAMAMOORTHY et al. (2010). Este esquema de particionamento da porosidade com base em perfis de imagem e de RMN estabelece que microporos correspondem a poros com diâmetro inferior a $0,5 \mu \mathrm{m}$; macroporos são poros com diâmetro superior à $5 \mu \mathrm{m}$ e os mesoporos estão entre os limites estabelecidos para micro e macroporos (diâmetro entre $0,5 \mu \mathrm{m}-5 \mu \mathrm{m})$. O fluxograma da Figura 2 resume as etapas de trabalho para a interpretação dos perfis geofísicos.

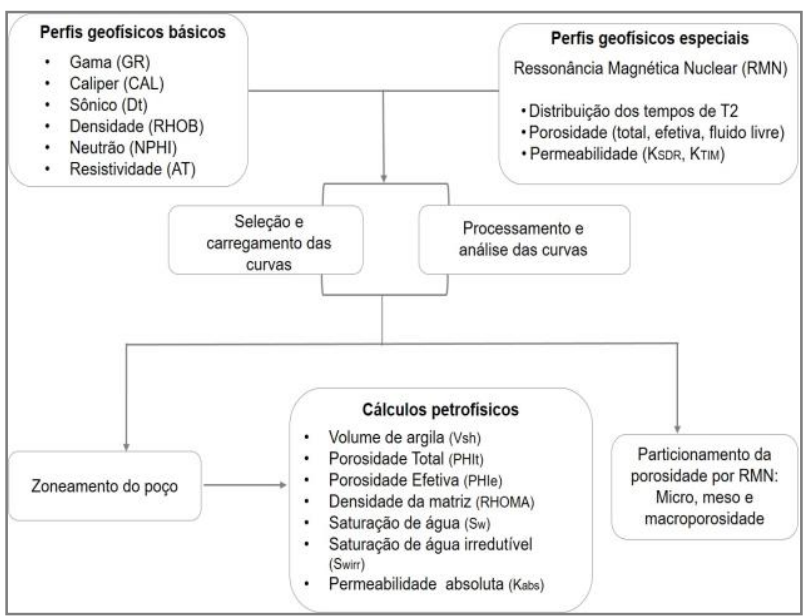

Figura 2 - Fluxograma das etapas para o tratamento e interpretação dos perfis geofísicos.

\section{Formação Barra Velha}

A Formação Barra Velha foi individualizada como unidade geológica datada no Eoaptiano (andar Alagoas Inferior). Suas principais litofácies são formadas por estromatólitos, esferulititos, mudstones, laminitos microbiais, microbialitos ricos em talco e argilas magnesianas e folhelhos carbonáticos depositados nas partes mais profundas e distais da bacia; todas estas fácies são atribuídas a depósitos formados in loco, sem evidências de retrabalhamento. As fácies de grainstones e packstones com fragmentos das rochas formadas in situ representam os depósitos provenientes de retrabalhamento. Coquinas e basaltos datados em 118 M.a. são esporádicos nos calcários da Formação Barra Velha (MOREIRA et al., 2007).

Estudos recentes a partir da integração dos dados de rocha, perfil e sísmica, viabilizaram a redescrição de muitas fácies deposicionais e novas interpretações sobre as associações de fácies e dos sistemas deposicionais. Os estromatólitos foram redescritos por ARIENTI et al. (2018) e SOUZA et al. (2018) como: a) calcários cristalinos arborescentes - arbustiformes (shrubby boundstones); b) travertinos e tufas acamadados; e c) boundstones microbiais laminados (incluindo laminitos microbiais). Os calcários cristalinos arbustiformes são agregados de cristais de calcita fascicular- ótica com extinção ondulante e padrão de ramificação divergente irregular, associados a argilitos silicáticos magnesianos como kerolita, estevensita e sepiolita, que ocorrem intercaladas às rochas carbonáticas. Os esferulitos estão frequentemente associados às argilas estevensíticas em fácies de argilitos laminados e wackestone - packestone esferulíticos. Dados petrográficos, geoquímicos (isotópicos e elementares) e de inclusão de fluidos sugerem que estas rochas possuem origem abiogênica, formadas a partir da precipitação química em ambientes hidrotermais e evaporíticos a temperatura ambiente, sob 
influência de fluidos ricos em Ca-Mg-Si associados a nascentes subaéreas e sub-lacustres. As rochas biogênicas são representadas pelos boundstones microbiais laminados (SOUZA et al., 2018) ou laminitos microbiais. Todos estes depósitos mostram intensa substituição e/ou cimentação por dolomita e quartzo com diferentes graus de dissolução.

\section{Resultados}

Os calcários da Formação Barra Velha no poço 1-RJS628 ocorrem no intervalo de $4947,80 \mathrm{~m}$ a 5243,80 m, com espessura total de 296 m. A sucessão carbonática neste poço é constituída por intercalações entre estromatólitos e esferulititos e suas fácies intermediárias denominadas "calcários esferulíticos-estromatolíticos", além de mudstones (maciços e laminados) e laminitos microbiais interestratificados aos estromatólitos e esferulititos. Dolomitos, margas (mudstones argilosos), silexito (chert) e folhelhos também se intercalam aos calcários em menor frequência. A mineralogia obtida a partir de perfis litológicos e de composição mineral no módulo Quant Elan (Techlog) mostraram que estas rochas apresentam como minerais básicos a calcita, dolomita, quartzo (microcristalino, denominado chert) e pirita. Indícios de hidrocarbonetos na forma de manchas e impregnações foram detectados nas profundidades de $4950 \mathrm{~m}$ a $5026 \mathrm{~m}$. Testes de formação detectaram a presença de óleo leve com 27,5ํA API (RFP-EX).

Para zoneamento do poço utilizou-se o perfil de raios gama (GR) e a curva de resistividade profunda em conjunto com as descrições de amostras lateral, calha e perfil composto para identificação das variações litológicas. Assim, dividiu-se a Formação Barra Velha em oito zonas: A, B, C, D, E, F, G e H (Figura 3). Nas zonas $F$ e $G$ nota-se o arrombamento do poço devido aos valores anômalos de cáliper nas profundidades entre $5115,9 \mathrm{~m}$ a $5139,69 \mathrm{~m}$. Neste intervalo de arrombamento se percebe que as curvas básicas foram afetadas e, para os cálculos petrofísicos, estas profundidades foram desconsideradas.

As zonas $A, B$ e $C$ são formadas por estromatólitos impregnados por óleo, mudstones argilosos maciços e/ou laminados e laminitos microbiais. Em menor frequência ocorrem esferulititos, margas, folhelhos, dolomitos e silexito. Estromatólitos e esferulititos são vugulares, apresentam matriz micrítica-argilosa, estão em parte recristalizados, cimentados e/ou substituídos em diferentes proporções. Estas zonas são as que apresentam maior quantidade de dolomita, quartzo e pirita. A zona A possui maior grau API em razão do maior conteúdo de argilas estruturais (sob a forma de laminações e estratos) e disseminadas na matriz carbonática (arcabouço da rocha). A porosidade NPHI varia de $0 \%$ a $23 \%$. Calcários argilosos apresentam porosidade baixa a moderada ( $\Phi$ NPHI médio $\leq 9 \%)$ e estão associados a calcários com dolomita e sílica; calcários limpos das zonas B e C (GR $\left.\leq 15^{\circ} \mathrm{API}\right)$ apresentam porosidade alta (ФNPHI $\geq 10 \%$ ) e estão mais recristalizados. Valores de resistividade profunda são altos $\left(R t_{\text {mín }}=58\right.$ ohm.m; Rt máx $=1693$ ohm.m; $R t_{\text {médio }} \geq$ 400 ohm.m); as curvas de resistividade rasa, média e profunda apresentam grande distanciamento entre si, caracterizando um expressivo perfil de invasão cujo o efeito annulus é observado a partir da inversão das curvas de resistividade (valores de resistividade média e/ou profunda são superiores aos valores de resistividade rasa) (Figura 4). Calcários porosos com óleo apresentam resistividade profunda entre 100 - 190 ohm.m; calcários pouco porosos (NPHI $\leq 6 \%$ ) e com óleo possuem alta resistividade ( $\geq 250$ ohm.m) devido a condição fechada de rocha e pela presença de óleo (ambos potencializam a resistência à passagem da corrente elétrica). A velocidade sônica para estas três zonas no geral é alta (47 a $64 \mu \mathrm{s} / \mathrm{ft}$ ) devido às porosidades baixas a moderadas que predominam nestas três zonas (Figura 3). A densidade varia entre 2,3 a $2,8 \mathrm{~g} / \mathrm{cm} 3$, onde as menores densidades estão relacionadas aos calcários mais porosos e/ou com sílica; as maiores densidades ocorrem em calcários com dolomita e pirita com variado grau de porosidade (arcabouço aberto ou fechado) (Figura 3). A saturação média de água para as 3 zonas é $45 \%$, onde a zona $A$ apresenta a menor saturação média de água $(S w=24,6 \%)$. A saturação de água irredutível é inferior a 1\% para as três zonas. Estas baixas saturações de água estão compatíveis com a baixa quantidade de água e significativa presença de óleo observada no perfil de fluidos nestas zonas. A permeabilidade calculada é bastante discrepante, variando de 0 até $1750 \mathrm{mD}$, com valores médios que vão desde $8 \mathrm{mD}$ até $94,7 \mathrm{mD}$ (Figura 5). A partir das curvas de distribuição dos tempos de relaxação transversal (T2) de RMN nota-se que os tempos de relaxação estão deslocados à direita do cut-off de 100 ms que separa a região de fluido aprisionado (à esquerda) da região de fluido livre (à direita), mostrando que o sistema poroso é caracterizado por poros na região de fluido livre (Figura 6). A partir do particionamento da porosidade se observa que a macroporosidade é o tipo de poro predominante nos calcários das zonas $A B C$, onde microporos perfazem menos de $1 \%$ do sistema poroso destas rochas (Figura 7).

As zonas D, E, F e $G$ são constituídas por calcários esferulíticos a estromatolíticos intercalados à laminitos microbiais, mudstones (maciços e /ou laminados), estromatólitos e esferulititos com matriz micrítica a argilosa. Todas as fácies apresentam intensa substituição e/ou cimentação por dolomita e pirita. Nestas zonas, os calcários são mais cristalinos e com menor teor de argila, tendência observada no baixo grau API das curvas de gama. Margas, dolomitos, chert e folhelhos ocorrem eventualmente intercalados aos calcários, especialmente na zona $G$, que apresenta maior quantidade de margas e/ou mudstones argilosos e folhelhos. Veios de quartzo ocorrem de forma esporádica ao longo das zonas e com maior frequência na base da zona $F$ (RFP-EX), próximo a zona de arrombamento. A porosidade nestes calcários é elevada, variando de $2 \%$ a $29 \%$ (Figura 3 ). Em virtude disso, as velocidades sônicas são baixas (52 a $88 \mu \mathrm{s} / \mathrm{ft}$ ). As curvas de resistividade se sobrepõem na maior parte do perfil, com raros perfis de invasão. A resistividade profunda é baixa, com valores médios e de mediana inferiores a 24 ohm.m. A saturação média de água para as quatro zonas é superior a $58 \%$, atingindo valores 
médios de até $80 \%$, esta grande quantidade de água também é observada no perfil de fluidos. A saturação de água irredutível apresenta valores médios superiores a $5 \%$. A permeabilidade calculada é baixa, variando de 0 até $151 \mathrm{mD}$, com valores médios inferiores a $4 \mathrm{mD}$ (Figura 5). As curvas de T2 de RMN mostram tempos concentrados à esquerda do cut-off de $100 \mathrm{~ms}$, demonstrando que o sistema poroso é dominado por poros na região de fluido aprisionado (Figura 6). A partição da porosidade destas zonas revelou que a micro e mesoporosidade são os tipos de poros predominantes nos calcários das zonas DEFG; onde os macroporos perfazem menos de $1 \%$ do sistema poroso destes carbonatos (Figura 7).

A zona $\mathrm{H}$ é formada por esferulititos com matriz micrítica predominantemente não-argilosa, eventualmente intercalados a margas, dolomitos e coquinas (esta última ocorre na base da zona $H$, próximo ao limite da Formação Barra Velha e Itapema). A mineralogia destas rochas é constituída predominantemente por calcita e percentuais menores de dolomita, chert e pirita. O baixo teor de argilas é identificado nas curvas de GR pelo baixo grau API. Em algumas profundidades foram descritas a ocorrência de fraturas em amostras laterais $(5112,5 \mathrm{~m})$. A porosidade média nestes calcários é elevada, superior a $10 \%$, variando de $0,2 \%$ a $22,5 \%$ (Figura 3 ). As velocidades sônicas variam de baixas a altas (49 a $87 \mu \mathrm{s} / \mathrm{ft}$ ). As curvas de resistividade formam um pronunciado perfil de invasão, no entanto, as resistividades não são tão altas quanto as das zonas $\mathrm{A}, \mathrm{B}$ e C, e nem tão baixas quanto as da zonas $\mathrm{D}, \mathrm{E}, \mathrm{F}$ e G. Nota-se que a expressiva presença de pirita e água (observada no perfil de fluidos) devem ter contribuído para a atenuação da resistividade nesta zona. A resistividade profunda é moderada, com valores médios de $14 \mathrm{ohm} . \mathrm{m}$ e máximos de até $170 \mathrm{ohm}$. A saturação de água e de água irredutível é alta ( $S w_{\text {média }}=60 \%$; Swirr médio $>5 \%$ ). Apesar da grande quantidade de água, o perfil de fluidos também mostra significativa quantidade de óleo. A permeabilidade calculada é moderada, variando de 0 a $29 \mathrm{mD}$ (Figura 5). As curvas de distribuição de T2 mostram tempos concentrados à direita do cut-off de 100 ms (Figura 6) em razão do predomínio de macroporos, onde microporos perfazem menos de $1 \%$ da rede de poros destas rochas (Figura 7).

\section{Conclusões}

As zonas de potencial reservatório de hidrocarbonetos foram definidas a partir da interpretação dos perfis acima detalhados em conjunto com as descrições litológicas dos relatórios de poço. Foram utilizados dez critérios para a definição de zonas dos reservatórios de hidrocarbonetos: 1) resistividade profunda acima de 100 ohm.m, 2) perfil de invasão identificado na separação das curvas de resistividade, 3 ) identificação do efeito annulus, 4) porosidade acima de $5 \%, 5$ ) saturação de água inferior a $50 \%, 6$ ) saturação de água irredutível igual ou inferior a $1 \%, 7)$ presença de óleo observado no perfil de mineralogia / fluidos, 8) permeabilidades médias acima de $3 \mathrm{mD}, 9)$ predomínio de macroporos, caracterizados por tempos de T2 concentrados na região de fluido livre, e 10) vestígios de óleo em amostras laterais.

Deste modo, os estromatólitos moderadamente argilosos das zonas $A, B$ e $C$ reúnem critérios favoráveis ao armazenamento e transmissão de hidrocarbonetos e, portanto, foram definidos como o "reservatório principal". Os calcários estromatolíticos-esferulíticos porosos das zonas $\mathrm{D}, \mathrm{E}, \mathrm{F}$ e G, apresentam condições desfavoráveis como rochas reservatório de óleo caracterizados pelas altas saturações de água e baixas permeabilidades devido ao predomínio de micro e mesoporos e, portanto, considerados como "não-reservatório". Os calcários esferulíticos da zona $\mathrm{H}$ foram classificados como "reservatório secundário" por apresentar características petrofísicas intermediárias entre um reservatório de hidrocarboneto e um não-reservatório.

O poço 1-BRSA-369A-RJS apresenta uma seção vertical de 140,2 m de calcários com óleo, o que corresponde a $47,36 \%$ da espessura total da Formação Barra Velha atravessada pelo poço.

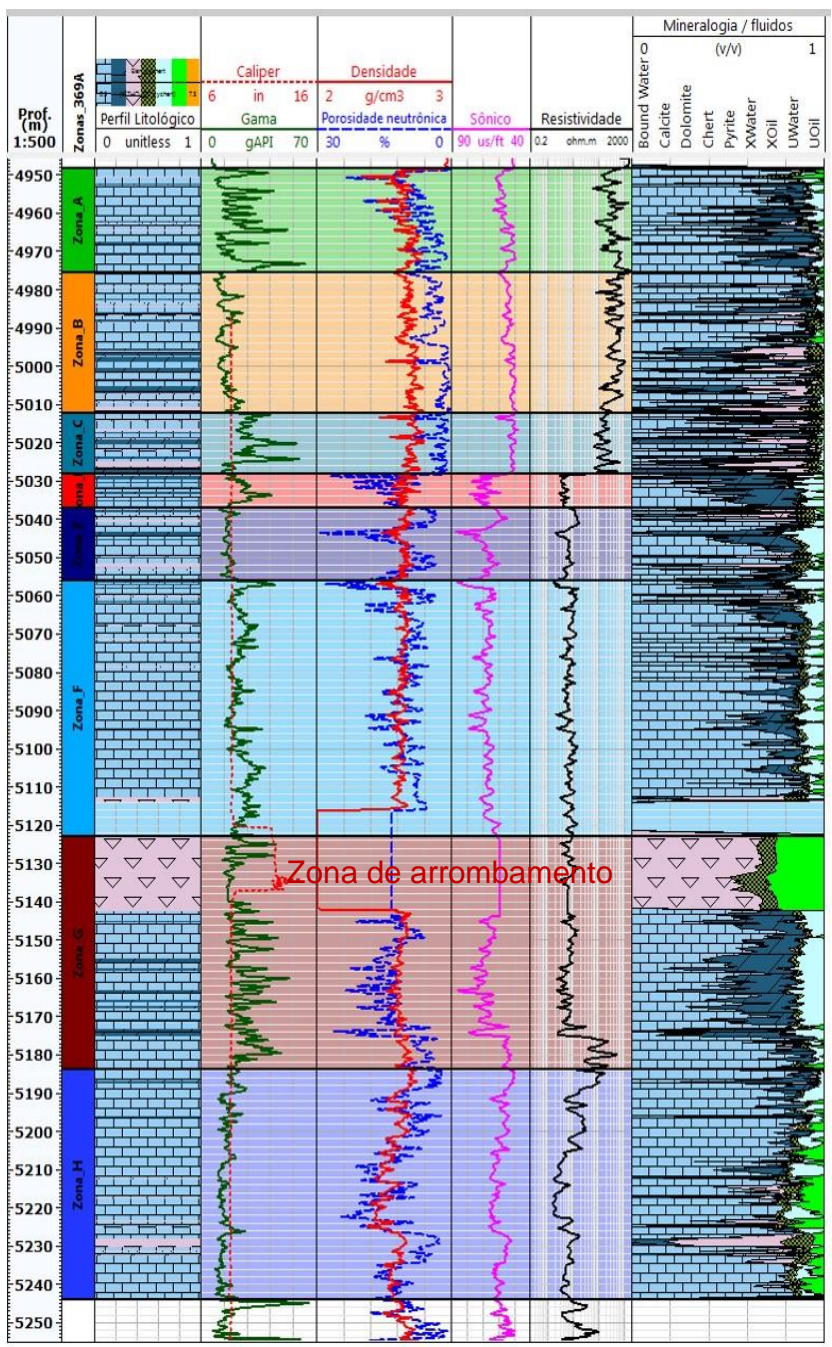

Figura 3 - Combo de curvas básicas (perfis litológico, gama e cáliper, nêutron-densidade, sônico, resistividade e perfil de mineralogia/ fluidos. 

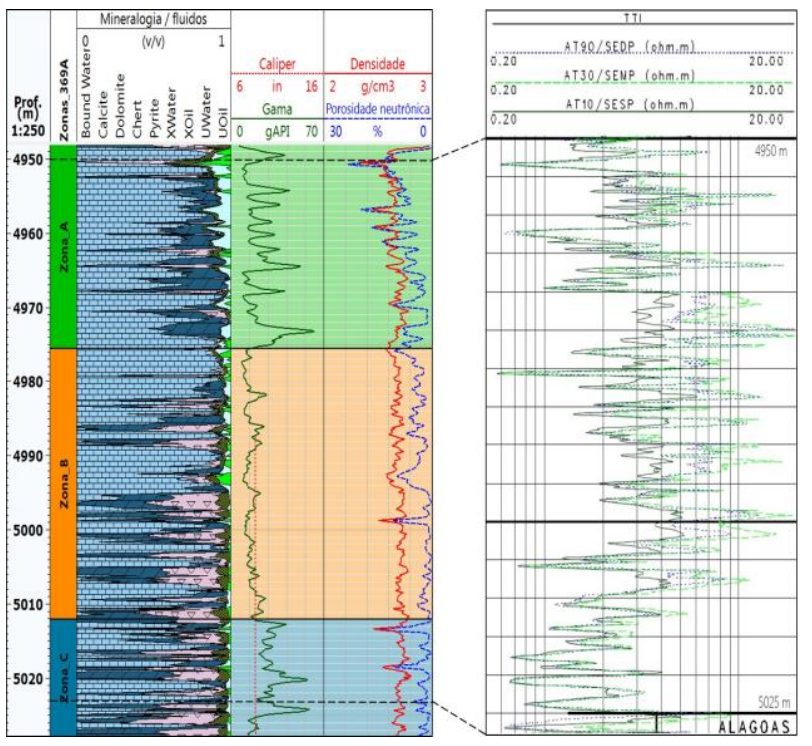

Figura 4 - Efeito annulus nas zonas $A, B$ e $C$ caracterizado pela inversão das curvas de resistividade: a curva de resistividade média se sobrepõe a curva de resistividade profunda e rasa. Essa condição ocorre em reservatórios com grande quantidade de óleo.

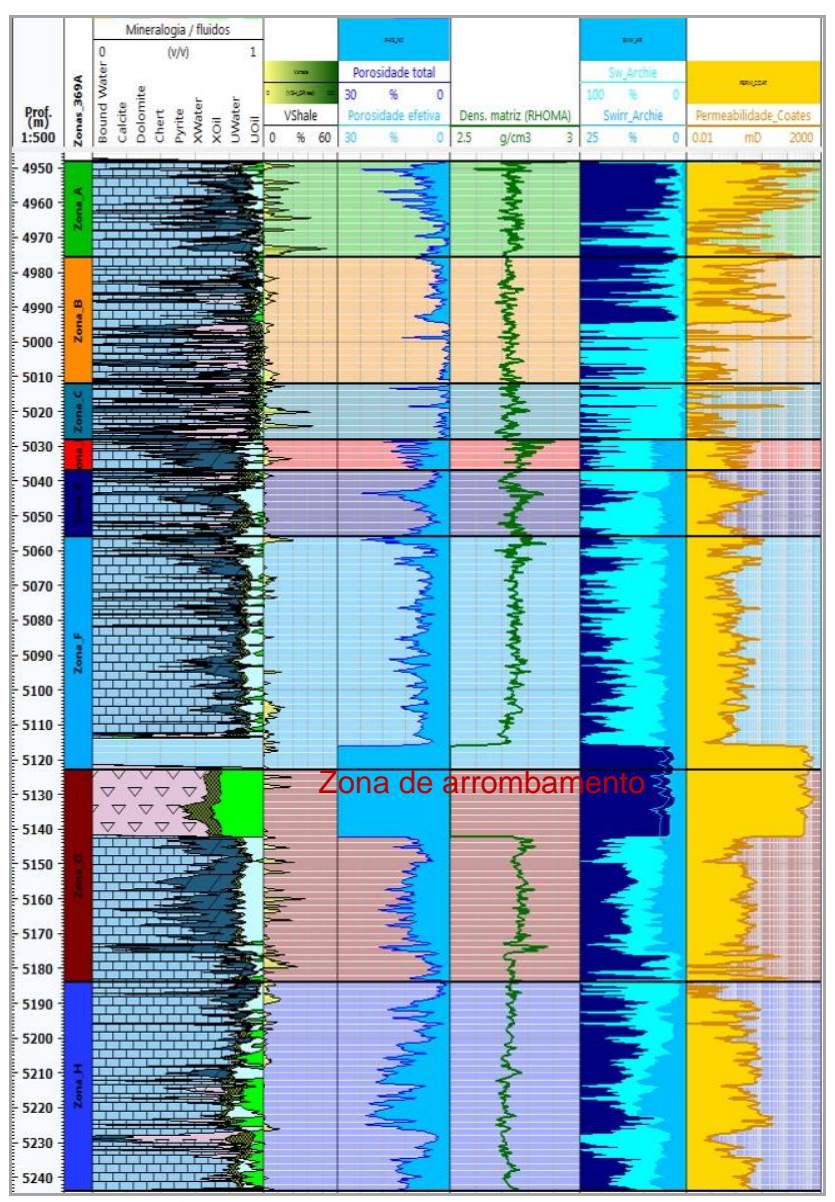

Figura 5 - Curvas calculadas a partir dos perfis básicos.

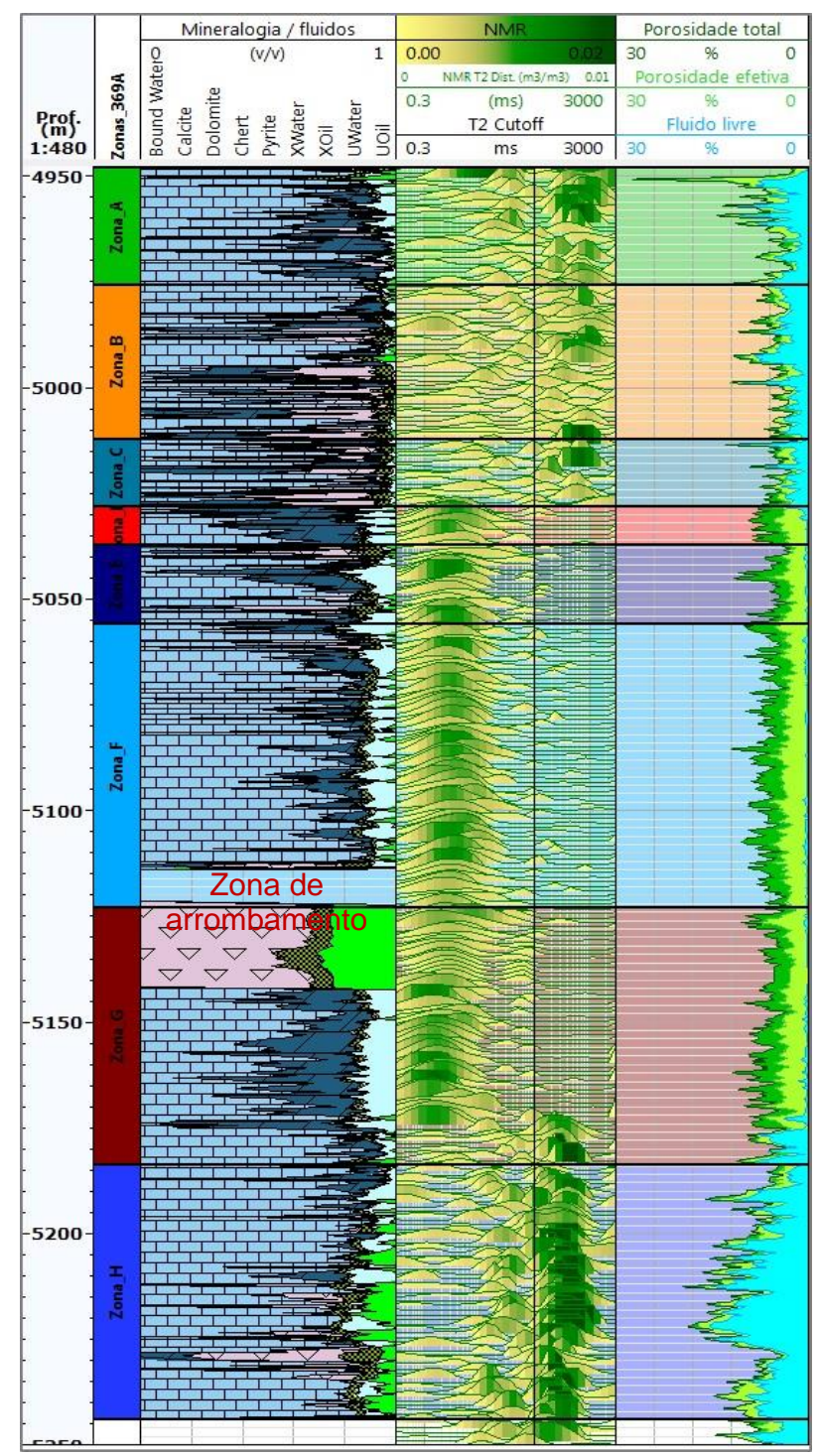

Figura 6 - Perfis de RMN: distribuição dos tempos de T2 e curvas de porosidade.

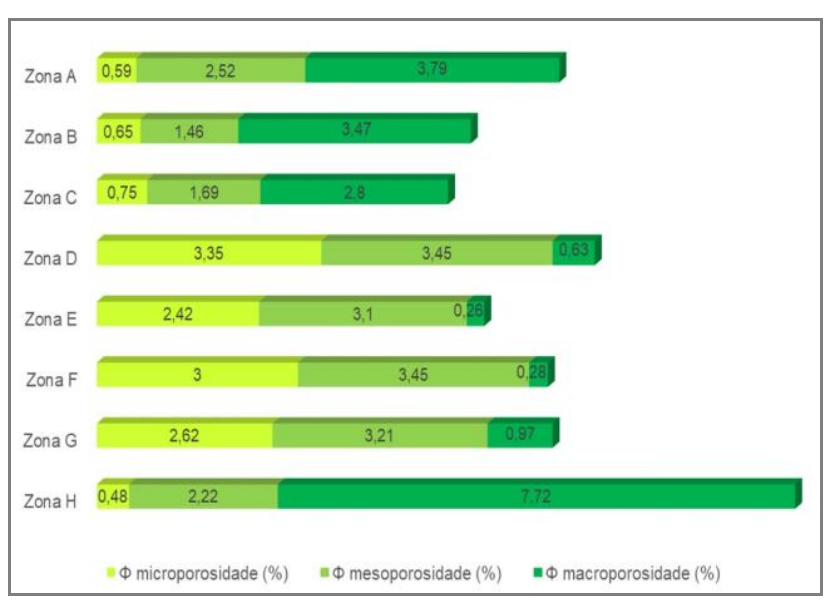

Figura 7 - Particionamento da porosidade das zonas com base nas curvas de T2 e de porosidades da RMN. 


\section{Agradecimentos}

As autoras agradecem à Agencia Nacional do Petróleo (ANP) pela disponibilização dos dados públicos de poço; ao Laboratório de Interpretação Sismoestratigráfica da Universidade do Estado do Rio de Janeiro (UERJ) pela infraestrutura computacional com acesso gratuito ao software Techlog, gentilmente cedido à Universidade pela Schlumberger, a quem estendemos nossos agradecimentos. Por fim, agradecemos ao geólogo Júlio Kosaka, assistente técnico especializado do Techlog, pelo auxílio na geração, processamento e interpretação dos perfis.

\section{Referências}

AGÊNCIA NACIONAL DO PETRÓLEO (ANP). 2019. Boletim de Produção de Petróleo e Gás Natural. Disponível em: <www.anp.gov.br/images/publicacoes/ boletins-anp/Boletim_Mensal Producao_Petroleo_Gas Natural/boletim-janeiro-2019.pdf>. Acesso em: 16 mar. 2019.

ARCHIE, G.E. 1952. Classification of carbonate reservoir rocks and petrophysical considerations. American Association of Petroleum Geologists Bulletin, v. 36, n.2, p. $278-298,1952$.

ARIENTI, L. M. et al. Facies Association, depositional Systems, and Paleophysiographic Models of the Barra Velha Formation, Pre-Salt Sequence - Santos Basin, Brazil. In: AAPG ACE CONFERENCE, 2018, Salt Lake City. Abstract... Salt Lake City: AAPG Search and Discovery \#2843310, 2018, 2p.

BOYD, A. et al. Pre-Salt Carbonate Evaluation for Santos Basin, Offshore Brazil. Petrophysics, v. 56, nº, p.577591, 2015.

CHANG, H. K. et al. Sistemas petrolíferos e modelos de acumulação de hidrocarbonetos na Bacia de Santos. Revista Brasileira de Geociências, v. 38, n. 2, p. 29-46, 2008.

COATES, G.R. et al. The MRIL in Conoco 33-1: An investigation of a new magnetic resonance imaging log. Transactions of the Society of Professional Well Logging Analysts, 32nd Annual Logging Symposium, Paper DD, $24 \mathrm{p}, 1991$.

HERLINGER JR., R; DE ROS, L. F; ZAMBONATO, E.E. Evolução da porosidade e permeabilidade dos reservatórios carbonáticos do Pré-sal do Norte da Bacia de Campos. In: RIO OIL \& GAS EXPO AND CONFERENCE, 2016, Rio de Janeiro. Anais... Rio de Janeiro, Instituto Brasileiro de Petróleo, Gás e Biocombustíveis-IBP, 2016.

HERLINGER JR., R; ZAMBONATO, E.E.; DE ROS, L. F. Influence of diagenesis on the quality of lower cretaceous pre-salt lacustrine carbonate reservoirs from nothern campos basin, offshore Brazil. Journal of Sed. Research, v. $87, \operatorname{pg} 1285-1313,2017$.
LIMA, B.M; DE ROS, L.F. Deposition, diagenetic and hydrothermal process in the Aptian Pre-Salt lacustrine carbonate reservoirs of the northern Campos Basin, offshore Brazil. Sedimentary Geology, v. 383, p. 55-81, 2019.

MACHADO,V. et al. Carbonate petrophysics in Wells Drilled with Oil-Based Mud. Petrophysics, v. 53, n4 p.285-292, 2012.

MOREIRA, J. L. P.; MADEIRA, C. V.; GIL, J. A.; MACHADO, M. A. P. Bacia de Santos. Boletim de Geociências da PETROBRAS, Rio de Janeiro, v. 15, n. 2, p. 531-549, 2007.

RAMAMOORTHY et al. A new workflow for Petrophysical and textural evaluation of Carbonate reservoirs. Petrophysics, v. 51, n. 1, p. 17-31, 2010.

SALLER, A. et al. Presalt stratigraphy and deposition systems in the Kwanza Basin, offshore Angola. AAPG Bulletin, v. 100, n. 7, p. 1135-1164, Jul. 2016. 